\title{
Saving the Planet or Saving the Brand? How Brand Strength Influences Consumers' Perceptions of Brand Sustainability
}

\author{
Patricia Rossi, Diego Costa Pinto, Marcia Herter, and Dilney Gonçalves
}

\begin{abstract}
Sustainability actions, such as ecolabels, are increasingly prevalent among companies. However, relatively little is known about consumer response to these actions for brands. The authors propose that the degree to which ecolabels enhance consumers' perceptions of brand sustainability depends on brand strength (i.e., the differential effect of brand knowledge on consumer response to the brand). Two studies demonstrate that brand strength changes the impact of ecolabels on consumers' perceptions of brand sustainability and purchase intentions. The findings suggest that consumers use ecolabels as cue for brand sustainability for weak brands (i.e., brands without significant positive brand equity), but not for strong brands (i.e., brands with significant positive brand equity). In addition, results suggest that sustainability mediates purchase intentions, but these effects are stronger for weak brands than for strong brands.
\end{abstract}

\footnotetext{
P. Rossi $(\bowtie)$

Grenoble Ecole de Management, Grenoble, France

e-mail: patricia.rossi@grenoble-em.com

D.C. Pinto

ESPM Business School, São Paulo, Brazil

e-mail: diego.pinto@espm.br

M. Herter

FADERGS, Porto Alegre, Brazil

e-mail: marcia.herter@fadergs.edu.br

D. Gonçalves

IE Business School, Madrid, Spain

e-mail: dilney.goncalves@ie.edu
}

L. Petruzzellis, R.S. Winer (eds.), Rediscovering the Essentiality of Marketing, 